\title{
Advertising Ethics and Professionalism of ZNBC Radio 4 and Radio Phoenix in Zambia -A Content Analysis Study
}

\author{
Fidelis Muzyamba1, Musonda Lemba ${ }^{2}$ \\ ${ }^{1}$ Department of Media and Communication Studies, University of Zambia, Lusaka, Zambia \\ ${ }^{2}$ Department of Population Studies, University of Zambia, Lusaka, Zambia \\ Email: fmuzyamba@unza.zm,mlemba@unza.zm
}

How to cite this paper: Muzyamba, F., \& Lemba, M. (2020). Advertising Ethics and Professionalism of ZNBC Radio 4 and Radio Phoenix in Zambia-A Content Analysis Study. Advances in Journalism and Communication, 8, 80-95.

https://doi.org/10.4236/ajc.2020.83007

Received: June 1, 2020

Accepted: August 25, 2020

Published: August 28, 2020

Copyright $\odot 2020$ by author(s) and Scientific Research Publishing Inc. This work is licensed under the Creative Commons Attribution International License (CC BY 4.0).

http://creativecommons.org/licenses/by/4.0/

\begin{abstract}
This study of ethics and professionalism in the content of Radio Phoenix and ZNBC Radio 4 was inspired by, among other things, occasional public controversies in Zambia over the content of advertising. It sought to examine the advertisements gathered over a period of one week after being aired during prime-time: before, during, and after the "Shopping basket" programme for radio Phoenix, and the 18:00 hrs. News summary for ZNBC Radio 4, to determine extent to which unethical and unprofessional advertising occurred. The sample is from 2012. The main research question was: To what extent does unethical and, or unprofessional advertising feature in radio broadcast advertising in the two stations? The alternative hypothesis being tested was: There was more unethical content in the private station than in the quasi-government/ public radio station. To effectively deal with the question and hypothesis, some sub-hypotheses were also tested to help arrive at a conclusion. The study found that, with respect to "ethical" and "unethical" conduct, there was a mixture of both, as well as incidence of both "professional" and "unprofessional" outputs.
\end{abstract}

\section{Keywords}

Professionalism, Ethics, Advertising

\section{Introduction}

The 1989-1990s winds of change which swept across Europe and the rest of the world, also affected Zambia politically, socially, and economically. The country which had once been a British protectorate named Northern Rhodesia, gained 
independence in 1964, before it became socialist in January 1970, after the Mulungushi Economic Reforms, which resulted in 51 percent stake of biggest companies being taken over by the state. With the winds of change mentioned earlier, the politically and economically monolithic socialist Second Republic gave way to capitalist democracy, especially after protests in 1989 and 1990 over food shortages and other economic hardships. In 1990, Kenneth Kaunda's government agreed to political reforms and allowed the return of multi-party politics to the country. With the return of democracy, also came economic choice and economic competition in the market place. The economic sphere once again came to be characterized by struggles of philosophies and practices in advertising which have led to the growth of self-regulation Advertising Practitioners Associations (APAs) elsewhere, even if Zambia had yet to create an APA at the time of writing.

Zambians often complain about poor advertising practices, and this for example, led to some protests in the 2001 over condom adverts that were deemed too explicit, and had to be pulled off the airwaves (The Humanitarian, 2001). In the same vein, some people have asked to have some form of advertising ethics body to enhance Professionalism (Genderlinks, 2011; Times of Zambia, 1999). Furthermore, there hasn't been a content analysis study of radio advertising ethics and professionalism in the country, and hence this study should help fill a gap in the existing knowledge, attitudes and practices of advertising.

\section{The Case for a Study of Advertising Professionalism and Ethics}

As indicated in the statement of the problem above, this study is expected to help provide data and ideas to solve problems in a situation where people in Zambia often complain about poor advertising practices, and some have asked to have some form of ethics body to enhance Professionalism (ibid.). A review of content analysis literature from other countries reveals similar concerns and worries (Nathanson-Moog, 1984; National Institute of Alcohol Abuse and Alcoholism, 2006; Finn \& Strickland, 1982). Among others, observations were made of unethical Advertising, e.g. airing of false adverts, and other unprofessional tendencies. The authors wrote that, in the USA, in order to sell, numerous advertisements emphasize unrelated socio-psychological themes, and 70 percent of the sampled adverts associated consumption of alcohol with "camaraderie" (Finn \& Strickland, 1982), while Atkin \& Block (1981) found "the most common appeals in TV and magazine alcohol ads to be Social camaraderie, escape, romance, and elegance.

Nuendorf K. A. (1985) also quoted Atkin \& Block, 1981 who found that respondents who had been heavily exposed to alcohol advertisements perceived the typical drinker as more fun loving, happier and better looking. He further cited a 1985 survey of his own with 100 adolescent respondents in the Cultivation theory tradition which showed that heavier TV viewers were significantly more likely to think "all people who drink are happy" and that "you have to drink to have fun at a sporting event." Furnham Adrian and Saar Alexandra 
March undertook a content analysis study of Gender-role Stereotyping in Adult and Children's Television Advertisements 2005. The study showed a slight decline in stereotyping in Britain, and slightly more stereotyping in Poland than in Britain (Furnham Adrian \& Saar Alexandra, March 2005).

\section{Gender Stereotyping in Adverts as Evidence of Unprofessionalism}

One glaring unethical and unprofessional conduct area is gender inequity. Contrary to suggested standards in professional Advertising Codes of Ethics, there is a tendency for male characters to be disproportionately represented as powerful, and the majority of females as weak, subservient, and merely ornamental (Genderlinks, 2011). Studies from Hong Kong and Indonesian Television showed that women in advertisements received advice and deferred to the more powerful male figure (Furnham Adrian, Mak Twiggy, \& Tanidjojo Liza, 2000). Furthermore, Furnham \& Spencer-Bowdage (2002), found that, in Britain and South Africa, 56.8 percent of females didn't present an argument in adverts, compared to 22.4 percent males. Such occurrences from around the world help buttress the argument that the matter of professionalism and ethics in advertising deserves attention from media scholars.

\section{Advertising Ethics}

Deontological Ethics hail from the word "Deon", from Greek for "duty", and "logos" or "science", because these are based upon something being moral because it is the "right" action, rather than depending on an assessment of consequences of an action (Encyclopaedia Britannica, 2020). In Deontological ethics, there are rules, or ethical standards, to follow, and one is expected to always abide by these if they are ethical. Consequently, the advertiser is expected to follow absolute standards, or norms, e.g. of truthfulness, fairness, and avoid cheating. To use another example, the practitioner is not expected to abuse, or take advantage of children, no matter what the circumstances. Deontologists have had considerable impact on ethics codes which almost invariably include exhortations to obey such standards in their practice. Their "dos" and "don'ts" provide pillars for such codes, even though they may not be helpful for situations where practitioners face moral dilemmas where, for example, truth-telling may harm someone.

A second major perspective is called teleological ethics. The term "teleological" is from Greek "Telos" meaning "consequence", "goal", or "end" (Encyclopaedia Britannica, 2020). Teleological or consequentialist ethics are also called utilitarian ethics. In this thinking, advertisers act for the best "ends", or "maximum good" for the most people, even if there may be, for example, an element of untruth in an advertisement. They suggest that the more good resulting from an act, the better it is, as summarized in the slogan "the greatest happiness for the greatest number" (Stanford Encyclopedia, 2020). This perspective, based on utilitarianism, supports "self-adjustment over strict, absolute restriction" (Kim, J. \& Kim, C., 2017), and it is permissible for some untruth as long as the ends of 
"the greatest number of people" as are being served. Such thinking could have the positive consequence of dis-inhibiting and freeing up the creative energies of advertisers, but it could also, in some circumstances, lead to excesses by some care-free practitioners, especially where there are no ethics advertising associations or complaints boards. Besides, something helping, or acceptable to a majority, may also cause harm to minorities. It is also possible that some offending ads are actually made by people who think they are serving a majority but end up misreading the situation.

Milton Friedman's ethics is an extreme form of teleological business ethics. The theory posits that a business firm's primary responsibility is to its shareholders, and this was captured in Freidman's 1970 explicitly titled New York Times Magazine article, "The Social Responsibility of Business Is to Increase Its Profits" (Freidman, 1970). This hard-nosed approach to ethics, now called the "Friedman Doctrine" places a premium on rights of the owners of business and calls this "social responsibility." The advertiser following this approach with its narrower definition of "Social responsibility" is less caring for sensibilities, or needs of the larger society. He/she ends up hard to distinguish from the one labeled as "unethical" by those operating from absolutist ethics persuasions, or even by those seeking "the greatest good, for the greatest number."

\section{Advertising Ethics at the Firm}

For practice, the situation is profoundly more complex. Indeed, Nordenstreng warned that codes of ethics may be seen as "mere window-dressing or camouflage, or at best manifestations of hypocrisy" (Nordenstreng, K., 1999) in situations where commercialism prevents the true application of the codes. Reilly, P. (2013) also expressed a similar view in a 2013 master's degree thesis when he wrote that some people argue that, in the sometimes rough and tumble world of competitive advertising, it is impossible to have morality (ibid.). Furthermore, the opinion of people regarding advertisers in countries such as the USA, is low, and this does not help the case for their claim to be professional or ethical in their work. In 2010, and 2019 Gallup polls on honesty and ethics in the USA, advertising practitioners came in third from last among professions in public perception of honesty and ethics, just ahead of lobbyists and car salespeople" (Gallup Poll, 2019; Gallup Poll, 2010; Reilly, 2013). A 1981 Newsweek poll which asked respondents to rate the honesty and ethical standards of professions found advertising executives to be the least trusted among the professions, just below congressmen (Schudson, M., 1984) in that country. This is partly due to what people believe to widespread incidence of unethical behavior as advertisers do their work (ibid.). By contrast, Nurses and Doctors, for example, scored very high ratings (ibid.). This is brought up here to help contextualize the study on broadcast media ethics and professionalism. Besides, some of the advertisers in Zambia are from transnational companies with roots in the west. Despite the Gallup studies having focused on advertisers, and not the radio stations themselves, the matter is pertinent because broadcast media are the paid conduits, or 
carriers of the content from the advertisers who originate it. If they accept and air it, it becomes their responsibility as well.

Advertising philosophy may differ from person to person, or from organization to organization, particularly in countries without good educational opportunities for advertisers. Even in developed countries, the matter of advertising philosophy is not straightforward, as a study of Ethics and values in advertising. two case studies, by Krueger (1998: pp. 53-65) showed.

In the 1998 study, evidence of values underlying advertising work were sought, not from the content but from US advertising agencies themselves (ibid.). Krueger conducted in-depth interviews with approximately 35 professionals from two advertising agencies located in one large city from whom he sought to find out the philosophies and values guiding the work of their agencies (ibid.) He found two basic value systems operating at the level of the advertising agency; one deontological, and strongly molded after the Christian tradition and encouraged by the agency president. The other was a more secular, teleological liberal approach to ethics and values (ibid.). The former agency had advertising that was more humane, but also suffered the impact of more limited business opportunities (ibid.). The latter was more aggressive, less humane, but also saw more leeway for business opportunities (ibid.). There was an interesting trade-off here between religious, conservative, advertising philosophy and cultural paradigm with relatively less profits on the one hand, and, on the other, a liberal and aggressive approach with less fetters, and relatively higher yields, profit-wise.

Evidently, stated another way, there were two philosophies of operation at work among owners and workers in the advertising agencies. First, the Secular Liberal-Individualist which might argue that professional advertising judgments must be separated from the moral and that individual creative personnel in a firm be given a chance to satisfy themselves as to whether to produce an advert or not (ibid.). This group also generally believe that consumers in the market were the best safeguards against bad advertising — not the advertising agency gatekeepers (ibid.).

Second, there were those subscribing to moral philosophy in which owners believed their advertising work to be consistent with a moral vision of the world (ibid.). Such philosophy translated into practice in which the owners/practitioners eschewed advertisements portraying what they saw as negative traits: aggression, sexist portrayals of women or men, harmful products such as tobacco or alcohol, as well as marginally or questionably beneficial products. In short, such owners sought to advertise in ways that promote positive social values.

Additional justification for standards or ethics obtains in the demands of Public Interest theory which posits that where we have common property resources such as the airwaves, it is helpful to keep in mind the public interest, and holds that markets are fragile and apt to operate inefficiently and inequitably if left alone, and that government is a neutral arbiter (Pigou, 1932). It posits that regulation (self, government or mixed types one might add-with a preference for self-regulation) is brought about in response to demand by the public and that 
regulation bodies operate on behalf of society and for prevention of excesses by certain vested interests (ibid.; Posner, 1974).

The first time a discussion of codes of ethics arose in business related professions was 1900 to 1917 when advertising practitioners in the USA's Midwest formed the first Associated Advertising Associations which they called Associated advertising Clubs of America (UK Essays in Marketing, 2018). In Kenya, the first milestone came in 1986 with the birth of Association of Advertising Practitioners (APA). In South Africa, the Advertising Standards Association (ASA) was established in 1968, before changing its name to the Advertising Standards Authority of South Africa (ASASA) and there is also the Advertising and Communications Practitioners Association (ACA). Nigeria now has Advertising Practitioners Council of Nigeria (APCON) set up under the Advertising Practitioners Act No. 55 of 1988, as amended by Act No. 93 of 1992 and Act No. 116 of 1993 (now Advertising Practitioners Registration Act Cap A7 of 2004 (APCON, 1988-2019); while the country also has the Nigerian Communications Commission assisting in oversight for advertising (Nigerian Communications Commission, 2020). It is a criminal offense for anyone to practice without registration with the council, and registration requires one to have a degree or diploma in advertising, mass communication, or other relevant field (ibid.). However, an examination is available for people without the requisite qualifications who still wish to practice (ibid.).

\section{Professionalism}

Wright, N (2002) articulated the following six pillars of professionalism:

1) Advanced studies in professional field; 2) Active membership of independent body committed to best practices in the field; 3) Active commitment to representing, upholding standards of the profession; 4) Active commitment to the development of knowledge, capability and good practice within field; 5) Active commitment to working under supervision with openness, integrity and transparency; and, 6) Active commitment to on-going learning and development.

Bowers Toni (2008) suggested there are three Pillars of Professionalism, namely: 1) Alignment (fit or supportive relations among the goals, processes, and other various key components), 2) Delivery (of output by the professional), and 3) Ethics (having good ideas about what is desirable, or what is right so that the organization has a moral campus). APM (2020) Suggested the following five dimensions of Professionalism: 1) Breadth of knowledge needed to competently perform a job-reflected in high standards or norms in the profession, 2) Depth, 3) Achievement, 4) Commitment to work and professional development through reading, etc., and 5) Accountability. Out of all these, only standards (ethics) are directly manifested or evidenced through the content under study-and hence the decision to look at evidence of poor, or bad adverts and to test whether its incidence is significant or not. There are a number of advertising codes of ethics Zambia can draw from, once she has an APA. 
Professional conduct demands ethical behaviour of a predictable standard. It is this dimension of professionalism that the researchers chose to use in the study. From codes of advertising ethics from international and regional sources, e.g. Advertising Standards Bureau of South Africa, Kenya's Advertising Practitioners Association, and the International Marketing and Advertising Code, the researchers settled for a number of indicators of ethics, and professionalism, and these were used in the study of the two Zambian radio stations. These are:

1) Difficulty in substantiating claims made in adverts

2) False advertising

3) Gender balance in creative personnel used in adverts

4) Gender-sensitivity in theme and stereotype portrayal

5) Use of disclaimers in Adverts

6) Gender balance in advertisement "Voice of authority"

7) Use of wrong illustrations

8) Explicit reference to sex

\section{Research Design \& Research Methods}

A mix of analytical and exploratory/descriptive research design was used in the study.

Method-wise, a quantitative content analysis after monitoring 136 radio advertisements was used to examine the professionalism and ethical dimensions of the advertisements aired by the broadcast stations of concern. The manifest rather than latent content was the subject of concern so as to be as objective as possible, and also to avoid unnecessary controversy sometimes arising from the uncertainties in interpreting latent-content. The Chi-square Test of Independence and Chi-square Goodness of fit tests of significance was used in the analytical part.

\section{Sampling Techniques for the Radio Advertisements}

All the adverts aired over a period of one week were used. Radio Phoenix and ZNBC Radio 4 in Lusaka were purposively chosen for the sample, out of 142 radio stations in Zambia.

This is because Lusaka has the greatest density of radio stations in the country, and the chosen two have national or near nation-wide reach. Lusaka is also the most affluent and largest advertising market (see Table 1). The broadcast industry is briefly as indicted in Table 2 .

ZNBC had the greatest reach of any broadcast station in Zambia and was the only truly national broadcaster in this sense (see Table 3). For instance, in 2012, ZNBC Radio 4 had about 2.5 million listeners in 2015.

Radio Phoenix has been placed as the radio station with the second-widest coverage, reaching a radius in excess of $643 \mathrm{~km}$, with a total listenership stood at 75 percent of the total population (Best of Zambia, 2020) which should be over 13.4 million people with Zambia's estimated 17,885,422 in 2020 (Zambia Statistics Agency, 2020). 
Table 1. Zambia's major advertising markets (2010 \& 2020).

\begin{tabular}{cccc}
\hline & POPULATION IN $\underline{\mathbf{2 0 1 0}}$ & POPULATION IN $\underline{\mathbf{2 0 2 0}} \mathbf{2 0 2 0}$ Projected B/down by Sex \\
\hline \multirow{2}{*}{ Zambia } & $13,092,666$ & $17,885,422$ & $8,852,174(\mathrm{M})$ \\
& \multirow{2}{*}{ Lusaka } & & $9,033,248(\mathrm{~F})$ \\
\hline \multirow{2}{*}{ Kitwe } & $1,327,000$ & $2,731,696$ & $1,343,733(\mathrm{M})$ \\
& 506,045 & 762,950 & $1,387,963(\mathrm{~F})$ \\
\hline \multirow{2}{*}{ Ndola } & 443,346 & 585,974 & $378,855(\mathrm{M})$ \\
& & & $384,095(\mathrm{~F})$ \\
\hline \multirow{2}{*}{ Livingstone } & 133,881 & 190,419 & $289,945(\mathrm{M})$ \\
& & & $296,029(\mathrm{~F})$ \\
\hline
\end{tabular}

Source: CSO (2010 Census of Population and Housing, Volume 11). F = Female; M = Male.

Table 2. Zambia's broadcast stations \& other telecommunications.

$\begin{array}{cc}\text { Radio } & 142 \\ \text { TV stations } & 45 \\ \begin{array}{c}\text { Microwave Communication } \\ \text { towers to improve access in rural areas }\end{array} & 776 \\ \text { Internet penetration } & 9.9 \text { million }=52 \text { percent (compared } \\ \text { to } 35.9 \text { percent continental average) }\end{array}$

Source: President's speech in parliament 6th March, 2020.

Table 3. Broadcast time \& peak slots for ZNBC radio \& TV.

\begin{tabular}{cccc}
\hline Channel & Broadcast Hours & Peak Time Slots & Coverage \\
\hline ZNBC Radio 1 & 24 Hours & $06.00-09.00,12-13,18-21.30$ & Whole Zambia \\
ZNBC Radio 2 & 24 Hours & $06.00-08.00,12.30-13.30,19.30$ & Whole Zambia \\
ZNBC Radio 4 & 24 hours & $06.00-13.30,17.30$ & Line of Rail \\
ZNBC TV1 & 24 Hours & $18.00-22.00$ & National \\
ZNBC TV2 & 24 Hours & $12.00-22.00$ & National \\
ZNBC TV3 & 24 hours & $17.30-24.00$ & National \\
\hline
\end{tabular}

Source: ZNBC 2020.

Radio Phoenix is widely listened to because of its prized "Let the People Talk" programme, comparative current affairs, and "presenter's maturity" (Lusaka Voice, 2013).

Each radio advertisement aired at the times of study during the approximately one week period of April 20-1st May 2012 was recorded for subsequent analysis. The choice of month of April was purposive, and connected to the fact that by then, the researchers would be ready to undertake the study. Further, the re- 
searchers did not see any problem since there are no indications that the matters of concern in the study problem followed a cyclical pattern, which could be affected by the choice of the study period.

As shown in Table 4 below, ZNBC Radio 4 and Radio Phoenix each had 68 apiece.

\section{Research question}

- To what extent does unethical and, or unprofessional advertising feature in radio broadcast advertising in the two stations?

\section{Hypotheses}

- $\mathrm{H}_{1}$ : There was more false advertising content in the private station than in the quasi-government/public radio stations.

To arrive at a reasonable conclusion, it was thought necessary to test the above hypothesis, as well as other hypotheses on the following specific ethical and professional indicators of ethical conduct or professionalism:

- Difficulty in substantiating claims made in adverts

- The presence of false advertising

- Use of disclaimers in Adverts

- Use of wrong illustrations

- Gender balance in characters

- Gender-sensitivity in theme and stereotype portrayal

- Gender balance in advert "Voice of authority"

- Explicit reference to sex

\section{Data Analysis and Findings}

The highest number of adverts was based on the "Construction industry" 18 (13.2 percent), followed by the "Hospitality industry and entertainment 15 (11 percent), see Table 5 below. In third place were "Public Service Announcements/Public Service Advert" 11 (8.1 percent). In lowest position were "Antiseptics, germicides, insecticides and disinfectants," "Cosmetics and make-up", "Financial services", “Transport and energy", "Internet and cellular telephony service providers", “Auction sales", "Phone accessories general advertisements", "Entertainment", and "manufacturing and supplies" each with 1 (0.7 percent).

Table 4. Sample size.

\begin{tabular}{cc}
\hline Station & Numbers in the Sample \\
\hline ZNBC Radio 4 & 68 \\
Radio Phoenix & 68 \\
Total= & 136 \\
\hline
\end{tabular}

Table 5. Top 3 Economic sectors represented in the radio adverts.

\begin{tabular}{ccc}
\hline Economic sector & Frequency & Percent \\
\hline Construction industry & 18 & 13.2 percent \\
Hospitality industry and entertainment & 15 & 11 percent \\
Public Service Announcements/Public Service Advert & 11 & 8.1 percent \\
\hline
\end{tabular}


As alluded to earlier, it has been suggested by observers that the pressure for profits makes it hard for advertising and other media to be ethical in their work (Krueger, 1998; Nordenstreng 1999; McQuail, 2010; Reilly, 2013) and this is compounded by beliefs by some in Teleological Ethics stressing on the ends justifying the means, and Freidman Ethics theory suggesting that loyalty of staff in a business is primarily to share holders, and not to e.g. the public or demands of professionalism, as Public Interest theory might suggest. This theoretical background led to the hypotheses on the selected dimensions being tested with the data obtained from this study.

Dimension: Type of Ownership and False advertising

$H_{1}$ : There is significantly more false advertising from Lusaka Private radio than you get from Quasi-government/ radio.

A chi-square test of independence was performed to examine the relation between Radio type (by ownership), and the incidence of false advertising. The relationship between these variables was not significant, $\chi^{2}(1, N=136)=1.007, p<$ 0.05 (see Table 6 and Table 7 below). The numbers of false advertising from each were almost the same (1.5 percent for the ZNBC Radio 4-a quasi-government/public station, and zero for the private Radio Phoenix-a private station. This shows that ownership type, and in particular, the often heard of pressures to make profit in private media and advertising (Krueger, 1998; Nordenstreng, K., 1999; McQuail, 2010; Reilly, 2013) apparently didn't affect the ethics of the private station as expected. Expressed in another way, perhaps professional advertising in Zambia has not been deeply affected by the extremity of Freidman Ethics, and advertisers still pay attention to concerns of other interest groups, and not just shareholders. In fact, the only incidence of false advertising was from ZNBC Radio 4 which was quasi-government/public.

\section{Dimension: substantiation of claims made}

$\mathrm{H}_{2}$ : A significant number of Lusaka radio adverts present difficulty in substantiating claims made.

A chi-square test of goodness of fit was performed to examine whether the number of adverts presenting difficulty in substantiating was the same as those which do not. The results was significant, but in a reverse sense-the percentage of adverts which presented difficulty in substantiating claims was negligible at 7/136 (5.1 percent...), compared to 129/136 (94.9 per cent) which did not (see Table 8 below). This shows good ethical and professional conduct on this dimension. Furthermore, with respect to substantiation of claims, there was no significant difference in performance based upon ownership type, and ZNBC Radio 4 only had 4/68 (5.9 percent) of its adverts presenting potential difficulty in substantiating claims made, while the corresponding figures for Radio Phoenix was a low 3/68 (4.4 percent).

\section{Dimension: False advertising}

$H_{3}$ : There is a significant number of false adverts aired by Lusaka radio stations.

A chi-square test of goodness-of-fit was performed to determine whether the 
number of false adverts was equally balanced that which was not. The numbers were not equally balanced, hence the results were significant (there was only once incident of false advertising out of 135), $\chi^{2}(1, N=136)=132.029, p>0.001$ (see Table 9 below). The proportion of false advertising was $1 / 136$ at 0.74 percent compared to $135 / 136$ or 99.3 percent which was not false, a result suggesting good ethical and professional output. Furthermore there was no significant difference in performance based upon ownership type, and there was only one false advert from ZNBC Radio 4 (1.5 percent of the station's sample, and none from Radio Phoenix).

Table 6. Medium * are there elements of false advertising? Crosstabulation.

\begin{tabular}{|c|c|c|c|c|c|}
\hline & & & \multicolumn{2}{|c|}{$\begin{array}{c}\text { Are there elements of false } \\
\text { advertising? }\end{array}$} & \multirow{2}{*}{ Total } \\
\hline & & & Yes & No & \\
\hline \multirow{9}{*}{ Medium } & & Count & 1 & 67 & 68 \\
\hline & ZNBC Radio 4 & Expected Count & 0.5 & 67.5 & 68.0 \\
\hline & & $\%$ within Medium & $1.5 \%$ & $98.5 \%$ & $100.0 \%$ \\
\hline & \multirow{3}{*}{ Radio Phoenix } & Count & 0 & 68 & 68 \\
\hline & & Expected Count & 0.5 & 67.5 & 68.0 \\
\hline & & $\%$ within Medium & $0.0 \%$ & $100.0 \%$ & $100.0 \%$ \\
\hline & \multirow{3}{*}{ Total } & Count & 1 & 135 & 136 \\
\hline & & Expected Count & 1.0 & 135.0 & 136.0 \\
\hline & & $\%$ within Medium & $0.7 \%$ & $99.3 \%$ & $100.0 \%$ \\
\hline
\end{tabular}

Table 7. Chi-square tests.

\begin{tabular}{cccccc}
\hline & Value & df & $\begin{array}{c}\text { Asymp. Sig. } \\
(2 \text {-sided })\end{array}$ & $\begin{array}{c}\text { Exact Sig. } \\
(2 \text {-sided })\end{array}$ & $\begin{array}{c}\text { Exact Sig. } \\
\text { (1-sided) }\end{array}$ \\
\hline Pearson Chi-Square & $1.007^{\mathrm{a}}$ & 1 & 0.316 & & \\
Continuity Correction $^{\mathrm{b}}$ & 0.000 & 1 & 1.000 & & \\
\hline
\end{tabular}

Table 8. Is there potential difficulty for substantiating claims made?

\begin{tabular}{cccc}
\hline & Observed N & Expected N & Residual \\
\hline Yes & $7(5.1 \%)$ & 68.0 & -61.0 \\
No & $129(94.9 \%)$ & 68.0 & 61.0 \\
Total & $136(100 \%)$ & & \\
\hline
\end{tabular}

Table 9. Are there elements of false advertising?

\begin{tabular}{cccc}
\hline & Observed N & Expected N & Residual \\
\hline Yes & $1(0.74 \%)$ & 68.0 & -67.0 \\
No & $135(99.3 \%)$ & 68.0 & 67.0 \\
Total & $136(100 \%)$ & & \\
\hline
\end{tabular}




\section{Dimension: Use of disclaimers}

$H_{4}$ : There is inadequate use of disclaimers by adverts aired on Lusaka Radio stations,

$$
\chi^{2}(1, N=136)=132.029, p<0.001 .
$$

A chi-square test of goodness-of-fit was performed to determine whether the numbers of use of disclaimers in advertising, and none-use were equally balanced. The presence of such data was not equally balanced, hence the results were significant, $\chi^{2}(1, N=136)=132.029, p<0.001$ (there was only once incident of use of disclaimers ( 0.7 per cent) out of 136.99 .3 percent of the radio adverts did not have disclaimers (see Table 10 below). Caution must be exercised in interpretation here because the reason some cases were shown to be without disclaimers may be due to the possibility that the nature of products and services adverted did not need any disclaimers. Again, there was no significant difference in performance based upon ownership type.

Dimension: Use of wrong illustrations

$H_{5}$ : There is a significant number of wrong illustrations in adverts aired by Lusaka radio stations.

A chi-square test of goodness-of-fit was performed to determine whether the use and non-use of wrong illustrations in radio advertising was equally distributed. The data was not equally balanced, so the result was significant, $\chi^{2}(1, N=$ $136)=128.118, p<0.001$ Most of the time (134/136 or 98.5 per cent) (see Table 11 below), correct illustrations were used, suggesting a significance in favour of good ethical and professional conduct. In terms performance vis-a-vis ownership type, there was no significant difference with respect to wrong illustrations. Only 2/68 (2.9 percent) of ZNBC Radio 4 adverts sampled) used wrong illustrations, while none of the privately owned Radio Phoenix adverts had wrong illustrations.

\section{Dimension: Gender balance in characters}

$H_{6}$ : Zambian advertisers on radio use significantly more men than women, in their adverts.

A chi-square test of goodness-of-fit was performed to determine whether the use of men in radio advertising, equaled that of women. The data was not equally balanced, so the result was significant, $\chi^{2}(2, N=136)=125.838, p<0.001$. A preponderance of men (107/136 or 78.6 percent) were used, compared to $15 / 136$ or 11 percent women, and 14/136 or 10.3 percent cases when both men and women were used (see Table 12 below). This result suggests unethical conduct and a lack of professionalism. This shows a lack of professionalism on this dimension of the study. However there was no significant difference between the number of male and female characters vs. type of ownership/type of station. Both types of station performed poorly.

Dimension: Gender sensitivity in theme and portrayal

$H_{7}$ : Radio adverts are not Gender-sensitive in theme and portrayal. 
A chi-square test of goodness-of-fit was performed to determine whether Radio adverts were Gender-sensitive in theme and portrayal. It was found that the data was not equally balanced, the result was significant, $\chi^{2}(1, N=136)=64.971$, $p<0.001$ Most of the adverts (115/136 or 84.6 percent) were not gender-sensitive, compared to $21 / 136$ or 15.4 percent which were (see Table 13 below). This shows a lack of professionalism on this gender dimension of the study. However there was no significant difference between the number of male and female voices of authority based on type of ownership/type of station. In other words both stations performed poorly on this particular gender dimension.

\section{Dimension: Voice of authority}

$H_{8}$ : A significant number of Radio adverts have significantly more male voice of authority figure.

A chi-square test of goodness-of-fit was performed to determine whether The number of adverts which have a male voice of authority was equally balanced with that which had females in that role. It was found that the data was not equally balanced, the result was significant, $\chi^{2}(3, N=136)=281.118, p<0.001$. The research revealed that there was also a preponderance of males featuring as "voice of authority" to conclude adverts (118/136 or 86.8 percent), compared to a paltry16 or 11.8 percent for females, as indicated earlier (see Table 14 below). One advert $(0.7 \%)$ had both male and female voices of authority, and another $(0.7 \%)$ had no "voice of authority." The preponderance of males on this score a lack of ethics and professionalism. However there was no significant difference between the number of male and female voices of authority based on type of ownership/type of station.

Table 10. Is there use of disclaimers?

\begin{tabular}{cccc}
\hline & Observed N & Expected N & Residual \\
\hline Yes & $1(0.7)$ & 68.0 & -67.0 \\
No & $135(99.3 \%)$ & 68.0 & 67.0 \\
Total & 136 & & \\
\hline
\end{tabular}

Table 11. Is there use of wrong illustrations?

\begin{tabular}{cccc}
\hline & Observed N & Expected N & Residual \\
\hline Yes & $2(1.4 \%)$ & 68.0 & -66.0 \\
No & $134(98.5 \%)$ & 68.0 & 66.0 \\
Total & $136(100 \%)$ & & \\
\hline
\end{tabular}

Table 12. Gender of characters in the adverts.

\begin{tabular}{cccc}
\hline & Observed N & Expected N & Residual \\
\hline Male & $107(78.7 \%)$ & 45.3 & 61.7 \\
Female & $15(11.0 \%)$ & 45.3 & -30.3 \\
Both male \& female & $14(10.3 \%)$ & 45.3 & -31.3 \\
Total & $136(100 \%)$ & & \\
\hline
\end{tabular}


Table 13. Is the theme/portrayal gender-sensitive?

\begin{tabular}{cccc}
\hline & Observed N & Expected N & Residual \\
\hline Yes & $21(15.4 \%)$ & 68.0 & -47.0 \\
No & $115(84.6 \%)$ & 68.0 & 47.0 \\
Total & 136 & & \\
\hline
\end{tabular}

Table 14. Voice of authority.

\begin{tabular}{cccc}
\hline & Observed N & Expected N & Residual \\
\hline Female & $16(11.8 \%)$ & 34.0 & -18.0 \\
Male & $118(86.8 \%)$ & 34.0 & 84.0 \\
Both male \& female & $1(0.7 \%)$ & 34.0 & -33.0 \\
Nil & $1(0.7 \%)$ & 34.0 & -33.0 \\
Total & 136 & & \\
\hline
\end{tabular}

\section{Dimension: Explicit portrayal of sex}

$H_{9}$ : A significant number of Radio adverts make explicit reference to sex.

All the Radio adverts avoided explicit reference to sex. This result was also in favour of ethical conduct and professionalism on the part of the stations studied, but that may not be representative of all situations. Indeed, the controversial explicit condom adverts referred to in the statement of the problem is a reminder of that.

\section{Conclusion}

The research study into ethics and professionalism in the two radio stations shows interesting results. The alternate hypothesis that there was more false advertising in private radio than in quasi-government/public radio was rejected. In fact, there was only one false advert from one of the stations. Other strengths included significantly low use of wrong illustrations, or those presenting difficulty in substantiating adverts, as well as the absence of explicit reference to sex. However, hypotheses on the gender indicators in the advertising content on the radio stations showed that the radio content failed to meet the required ethical and professional standards. The radio adverts showed a disproportionate tendency towards domination by males. One useful recommendation to remedy the wrongs, is that Zambia should go ahead and implement the long-postponed idea to establish a self-regulating professional body such as an Advertising Practitioners Association, or similar body, complete with codes of ethics to guide members, and a complaints body to handle grievances.

\section{Conflicts of Interest}

The authors declare no conflicts of interest regarding the publication of this paper. 


\section{Acknowledgements}

Prof. Kaarle Nordenstreng is acknowledged as Co-Supervisor of the doctoral dissertation on which this study is based.

\section{References}

APCON (1988-2019). Advertising Practitioners Council of Nigeria. https://apcon.gov.ng/

APM (2020). APM FIVE Dimensions of Professionalism. https://www.apm.org.uk/about-us/apm-5-dimensions-of-professionalism

Atkin, C., \& Block, M. P. (1981). Content and Effects of Alcohol Advertising. Springfield, VA: National Technical Information Service.

Best of Zambia (2020). The Best of Zambia. https://thebestofzambia.com/orgs/radio-phoenix

Bowers, T. (2008). The Three Pillars of Professionalism. https://www.techrepublic.com/blog/career-management/the-three-pillars-of-professio nalism

Encyclopaedia Britannica (2020). http://www.britannica.com/EBchecked/topic/133435/conservatism/237317/General-ch aracteristics

Finn, T. A., \& Strickland, D. E. (1982). A Content Analysis of Beverage Alcohol Advertising: II. Television Advertising. Journal of Studies on Alcohol, 43, 964-989. https://psycnet.apa.org/record/1983-31488-001 https://doi.org/10.15288/jsa.1982.43.964

Friedman, M. (1970). The Social Responsibility of Business Is to Increase Its Profits. The New York Times Magazine.

Furnham, A., \& Saar, A. (2005). Gender-Role Stereotyping in Adult and Children's Television Advertisements: A Two-Study Comparison between Great Britain and Poland. Communications, 30, 73-90. https://doi.org/10.1515/comm.2005.30.1.73

Furnham, A., \& Spencer-Bowdage, S. (2002). Sex Role Stereotyping in Television Advertisements: A Content Analysis of Advertisements from South Africa and Great Britain. Communications, 27, 457-483. https://doi.org/10.1515/comm.2002.003

Furnham, A., Twiggy, M., \& Liza, T. (2000). An Asian Perspective on the Portrayal of Women in Television Advertisements: Studies from Hong Kong and Indonesian Television. Journal of Applied Social Psychology, 30, 2341-2364.

https://doi.org/10.1111/j.1559-1816.2000.tb02440.x

Gallup (2010). Honesty and Ethics in the Professions. https://news.gallup.com/poll/145031/honesty-ethics-professions-pdf.aspx

Gallup (2019). Honesty and Ethics in the Professions. https://news.gallup.com/poll/1654/honesty-ethics-professions.aspx

Genderlinks (2011). Zambia: TV Ads Threatening Women's Gains. https://genderlinks.org.za/programme-web-menu/zambia-tv-ads-threatening-womensgains-2011-02-08

Gerbner, G., Gross, L., Morgan, M., \& Signorielli, N. (1982). Living with Television: The Dynamics of the Cultivation Process. London: Institute of Alcohol Studies.

Kim, J., \& Kim, C. (2017). Three Perspectives about Ethical Value in Advertisement Business. IJJMC, 3, 124.

https://www.scribd.com/document/414001501/Article-IJJMC-124 
Krueger, D. (1998). Ethics and Values in Advertising: Professional Identities and Organizational Cultures. St. Petersburg, FL: Poynter Institute.

Lusaka Voice (2013). Zambia’s Most Listened to Radio Stations. http://www.lusakavoice.com/2013/09/21/highlight-zambias-most-listened-to-radio-stat ions

McQuail, D. (2010). Mass Communication Theory. London, SAGE.

Nathanson-Moog, C. (1984). The Psychological Power of Ethnic Images in Advertising. In L. H. Fuchs (Ed.), The American Kaleidoscope: Race, Ethnicity, and the Civic Culture (pp. 19-22). Middletown, CT: Wesleyan University Press.

National Institute of Alcohol Abuse and Alcoholism (2006). Underage Drinking-Why Do Adolescents Drink, What Are the Risks, and How Can Underage Drinking Be Prevented? https://pubs.niaaa.nih.gov/publications/AA67/AA67.htm

Nigerian Communications Commission (2020). Guidelines on Advertisements and Promotions.

https://www.ncc.gov.ng/docman-main/legal-regulatory/guidelines/52-guidelines-on-ad vertisements-promotions/file

Nordenstreng, K. (1999). European Landscape of Media Self-Regulation, in Freedom and Responsibility Year Book. http://www.osce.org/fom/13577?download=trueVienna

Nuendorf, K. A. (1985). Alcohol Advertising and Media Portrayals. Journal of the Institute for Socioeconomic Policy, 10, 67-78.

Pigou, A. C. (1932). The Economics of Welfare. London: MacMillan \& Co.

Posner, R. (1974). Theories of Economic Regulation. Bell Journal of Economics and Management Science, 5, 335-358. https://doi.org/10.2307/3003113

Reilly, P. F. (2013). Advertising Ethics: A Client Perspective. MA Thesis, Columbia, MO: University of Missouri.

Schudson, M. (1984). Advertising the Uneasy Persuasion. New York: Basic Books.

Stanford Encyclopedia of Philosophy (2020). Kant's Philosophy of Religion.

The Humanitarian (2001). Condom Adverts Deemed Too Explicit. https://www.thenewhumanitarian.org/report/16654/zambia-condom-adverts-deemed-t oo-explicit

Times of Zambia (1999). Aggressive Advertising Works. Ndola: Times of Zambia.

UK Essays in Marketing (2018).

https://www.ukessays.com/essays/marketing/socio-cultural-aspects-in-consumer-banki ng-sector-marketing-essay.php

Zambia Statistics Agency (2020). Census Statistics. https://www.zamstats.gov.zm

ZNBC (2020). Advertising Rates. Unpublished. 